\title{
The Trouble with Burawoy: An Analytic, Synthetic Alternative
}

\section{Neil McLaughlin}

McMaster University

I Kerry Turcotte

McMaster University

\begin{abstract}
As American Sociological Association (ASA) president in 2004, Michael Burawoy argued 'for public sociology', sparking impassioned debate focused almost exclusively on the normative issues raised by his prescription for a more public sociology. Nearly absent from the literature is an analytical critique of his underlying model of the structure of sociological practice. The model is flawed in three ways: (I) the core concepts are ambiguous; (2) the model provides little leverage for understanding the institutional context of sociology as a discipline; and (3) comparative understanding of sociologies in different countries or between public engagement in distinct academic disciplines is not facilitated. In this article, we propose a synthetic means of relating academics, disciplines, audiences and institutional environments that forms the basis for movement toward an empirical agenda on public academics more generally.
\end{abstract}

\section{KEY WORDS}

academic disciplines / Burawoy / comparative sociology / public intellectuals / public sociology / sociology of knowledge

he theme of this special issue, 'Sociology and its Publics', is timely for British and North American sociology. In North America, there has been much discussion of the relationship between sociologists and their publics. As ASA president in 2004, Berkeley sociologist Michael Burawoy delivered the address, 'For Public Sociology' (2005), a prescription for revitalizing sociology for the 21st 
century. Given the institutional transformations we are seeing in the contemporary research university, the budget situation throughout public institutions in the West and the legitimacy crisis we are experiencing in the social sciences and humanities in these neo-liberal and scientistic times, Burawoy's manifesto for a relevant sociological imagination has generated great interest and debate in Britain (particularly in a 2005 special issue of the British Journal of Sociology entitled 'Continuing the Public Sociology Debate') as well as globally.

There has been a gap, however, in the debate about Burawoy's public sociology. We have not seen enough discussion of how one could empirically test Burawoy's claim that the health of the discipline is based on an unspecified balance between the four competing, yet complementary 'faces' of sociology: professional, policy, critical, and public. The model proposed by Burawoy is not empirically derived, nor are there clear routes to debating its values using empirical evidence. Criticism of Burawoy's model of sociology has centred on the normative and political issues raised by his prescription for revitalizing 21 st-century sociology. ${ }^{1}$ Normative debate about the kind of sociology we would like to see in the future is an essential component of a healthy discipline, and Burawoy's ideal types, to be sure, are designed for somewhat different questions than the empirical issues we are raising here. Nonetheless, from our perspective, an empirical sociology of sociology provides important evidence and analysis that can ground our disciplinary debates in more than ideology, professional selfinterest or personal preference.

\section{The Trouble with Burawoy's Public Sociologies: An Analytic Critique}

Burawoy's account of how sociology's four tasks are divided along the lines of audience and type of knowledge is worth spelling out before getting to our critique. Knowledge produced for academic audiences is either professional (instrumental knowledge generated by programs of scholarly research) or critical (reflexive knowledge raising the moral and normative aspects of the discipline). Outside of the academy, sociological knowledge is either policy oriented (instrumental knowledge generated to address a problem defined by a client) or public (reflexive sociological knowledge about issues that some public is interested in discussing). For Burawoy, these quadrants exist in an uneasy but productive symbiosis: professional sociology provides the foundational training and skills for work done in the other three quadrants. The nature of sociological careers means

Table I The sociological division of labour

\begin{tabular}{lll}
\hline & Inside University & Outside University \\
\hline Instrumental & Professional & Policy \\
Reflexive & Critical & Public \\
\hline
\end{tabular}


that scholars may occupy any or all of these quadrants at various times. Burawoy's 11 theses cover much ground beyond the simple prescription that we should be doing more - and better - public sociology, but it is this $2 \times 2$ table that has anchored the ensuing debate.

While the debate about public sociology has generated excitement, and a renewed sense of purpose as sociologists, Burawoy's rhetorical accomplishments hide some of the problems in his analytical categories. His model is not yet theorized in ways that provide space for an empirical agenda on public sociology. Our current concern is with making Burawoy's prescriptive model of public sociologies more empirically testable. We have examined the range of criticism focusing on ideological and conceptual assumptions in detail elsewhere (McLaughlin et al., 2005), and will not be revisiting these issues in detail here. For our purposes, there are three important challenges to Burawoy's model of sociology and its various publics: the conceptual, the contextual, and the comparative.

First, there is the issue of the ambiguity of Burawoy's core concepts. Some critics (Acker, 2005; Calhoun, 2005; and Tittle, 2004) have indicated that they are unclear what Burawoy's categories actually mean. The concepts critical, reflexive, and public are ill defined, heavily contextual, and highly contested in sociology. What is clear about Burawoy's use of these terms is that he is assuming that both public and critical sociology are inherently reflexive - an assumption that does not have empirical justification. ${ }^{2}$

Part of the problem is the myriad ways that Burawoy's core concepts are used by social science and humanities scholars. Lynch (2000) provides an excellent typology of the range of meanings of reflexivity, while Hammersley (2005) tackles a parallel problem with meanings of 'critical'. The various possible meanings of 'public' have been explored by several of Burawoy's commentators, and the literature extends well beyond this debate with regard to all three of these terms. Developing empirically useful operationalizations of these concepts is an important first step in the process of engaging in empirical work on public sociologies and public academic engagement more generally. Without clear and unambiguous meanings to the core theoretical categories in the model, we will never be able to empirically explore public sociologies.

The second problem is that the $2 \times 2$ model does not help us represent the institutional context for knowledge production. The $2 \times 2$ table does not allow us to theorize how Burawoy's four ideal types relate to each other, nor how individual tasks or the discipline as a whole are linked to external institutions and audiences. Neither does the $2 \times 2$ table help us examine the larger institutional context in which we must locate both sociology and its publics (the producers and consumers of public sociological knowledge). Burawoy discusses policy versus $p u b$ lic sociologies - two types of sociology linked to extra-academic institutions, organizations and networks. But Burawoy's $2 \times 2$ table cannot help us study the environment in which these policy makers and publics are located in any meaningful way. This makes discussion of the relationship between the academy and the public excessively vague and general in Burawoy's account. 
The third problem - comparison - grows out of this contextual vacuum. Responses to Burawoy's model have also ignored its limited capacity for comparative analysis. ${ }^{3}$ This is true at various levels of analysis: the text, the task, the scholar, the career, the department, the discipline, and at the level of national sociologies. The $2 \times 2$ table does not allow us to visualize the difference in the 'sizes' of each type of sociology in a particular department or in a national sociology. Burawoy's model furthermore does not help us compare sociology to other academic disciplines with regard to interlocks with extra-academic institutions, the relative importance of each 'type' of activity (policy, professional, critical, and public), and the distinct ways different disciplines engage (or do not engage) various and different publics. Finally, to the extent that we are able to look outside American sociology as we must, Burawoy's model does not go far enough in helping us provincialize sociology in America by comparing it to sociology in other countries. The $2 \times 2$ table is a universal Parsonian-style model that applies to sociology everywhere, something that we find unconvincing and goes against the spirit of Burawoy's own energetic and inspiring rhetoric in favour of a truly global sociology that moves beyond American dominance and false universalism.

Sociology needs to be understood analytically in relation to a real analysis of other disciplines and across national contexts. We need to locate sociology and its publics in a larger, comparative framework than offered in Burawoy's presidential address. In order to do this, we start with a production of knowledge perspective put forth by Steven Brint (1994), so that the institutional relationships that influence knowledge production can be mapped as part of the context for the professional activities we are interested in understanding. We then attempt to synthesize a revised version of Burawoy's concepts with the institutional mapping provided to us by Brint, highlighting, for now, the differences between American and Canadian sociology, sharing a few brief comments on British sociology and comparing sociology in the USA to economics. In this essay then, we attempt to address problems of both institutional analysis and comparative perspective in a conceptual way with an eye to the development of future empirical examinations of public sociologies and public academics.

\section{Comparison and Context: Steven Brint's Spheres of Knowledge Production}

Brint explores knowledge production by professionals situated in five distinct but interacting and overlapping - 'spheres of social purpose' (1994). The spheres of social (or related) purpose (SSP) are distinguished one from another as 'sets of interrelated occupations and organizations' (1994: 45). This framework answers the questions, 'knowledge about what?' and 'knowledge for what?', at the macro level but can also help us develop micro-level answers to these questions. Brint marks the boundaries between spheres based on the distinct forces driving each sphere, and on their distinct fundamental purposes. The five spheres are: 


\title{
Governance and Civic Regulation
}

\author{
law Schools Applied Sciences \\ Bioengineering \\ Computer Sciences
}

\section{Business}

Business Schools

Political Science

Economics

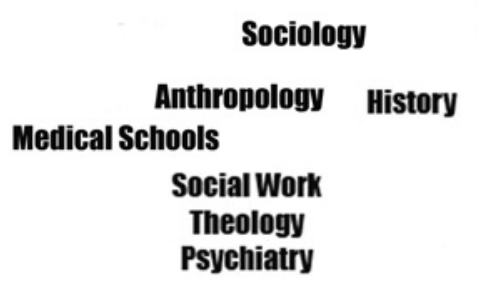

Philosophy

English

Philosophy

Journalism Schools

Theology

Psychiatry

\section{Human Services}

\section{Communication}

(1) the business services sphere, driven by profit and responsible for the production of goods and services

(2) the applied science sphere, driven by technical puzzles to generate technological innovation

(3) the culture and communications sphere, driven by public consumption of information and entertainment to produce these cultural products and expressions

(4) the civic regulation sphere, ${ }^{4}$ in which governance is accomplished through democratic processes and bureaucratic politics; and

(5) the human services sphere, which is driven by the need for the reproduction of human individuals to pursue human health and socio-economic wellbeing.

Figure I The university in its instrumental context

Brint's work allows us to consider where the university fits in to the extraacademic world. Figure 1 below maps Brint's (1994) five main spheres of social purpose, and begins the process of locating various academic disciplines and applied schools. For the purposes of illustration only, we have represented some of the core liberal arts disciplines (sociology, anthropology, history, English, political science, and economics) as well as some applied programs that are sometimes organized as majors or sometimes organized into separate faculties or schools (business, journalism, social work, computer science, and engineering), approximating their relationship to the outside spheres. We have also 
represented some of the most important traditional professional schools that exist in contemporary research universities (law, medical and business schools).

What Brint is allowing us to do, then, is to think about how disciplines or schools as discrete sub-spheres of social purpose are linked, in differential ways, to extra-academic institutions. It seems sensible, for example, that law schools, while part of the university complex, are more closely tied to concerns that emerge from the sphere of governance and civic regulation, than they are linked to culture and communication. Business schools have obvious linkages to the business SSP; engineers to the applied sciences SSP; and social work and education to the human services SSPs. We are somewhat limited by the need to conceive of disciplines or schools in ideal-typical ways and by the two-dimensional nature of the map. And various disciplines have multiple links to different spheres (the entertainment industry, for example, is dominated by the profit motive of private media corporations and could be linked to business as well as culture and communications), and the questions are politically loaded, intellectually contested, and historically and comparatively varied. Our representation of an ideal type of selected disciplines in contemporary North American research universities is not designed to resolve these complex theoretical and empirical questions, but to illustrate the fact that Burawoy's model does not go as far as it could in helping us think about the differences between, say, policy work in the governance sphere as compared to policy work for business or the applied sciences. ${ }^{5}$ In the next section, we present a synthetic way of thinking about the issues of context and comparison, using a model that combines Burawoy's (2005) basic categories with Brint's (1994) spheres of social purpose to allow us to capture more of the rich conceptual and contextual detail of the relationship between sociology and other academic disciplines and their various audiences.

\section{Contextualizing and Comparing Academics and their Publics}

We are providing a graphic model of what can be done by synthesizing elements of Burawoy and Brint. From Brint we take a model of the larger institutional/intellectual/cultural environment in which the university and discipline are embedded. This is nuanced by Burawoy's categories of professional, policy, public, and critical. Taken together, these models can be used in ways that apply beyond one-dimensional discussions of a single discipline in a particular national context (or worse, in an apparently nationless context that is anything but). We now have a framework that can be used comparatively and will allow us look at public sociology as a particular form of knowledge production that occurs as the result of interactions between academics and various institutions and publics.

The model allows us to potentially answer the question: what would policy, public, professional, critical work in various disciplines (sociology, history, economics, etc.) look like in the distinct spheres of governance, applied science, business, culture and communications, and human services? For example, in 
sociology, Diane Vaughan's Challenger Launch Decision (1996) is an example of policy sociology (albeit accidentally, and after the fact) that shaped policy in the applied sciences sphere and governance sphere - her sociological study of organizational behavior influenced how NASA responded to space shuttle accidents (Vaughan, 2006). In addition, Vaughan's book Uncoupling (1986) is one example of professional-turned-public sociology: it sold over 200,000 copies and people outside professional social science read it as a mass market book (albeit on the intellectual high end) that helps them make sense of their own divorces.

Cynthia Fuchs Epstein's work on the women in the law profession (1981) represents a type of non-governmental policy sociology as well as professional and public sociology, something which is more common in business schools and among economists, but that obviously occurs in sociology. Epstein's professional sociology research and writing on gender in the law profession has had influence on how some legal professionals think about policy in their organizations, and some of her more recent work is policy sociology funded by the New York State Bar. In addition, general readers interested in law and gender read Epstein's work, giving it a public as well as a professional component. While Vaughan's work shapes policy in the applied science sphere and public discussion in the human services sphere, Epstein's writings are relevant to the policy in both the governance sphere and among private sector law firms.

The synthetic model we are proposing allows us to capture nuances that are lost in Burawoy's 'policy' and 'public' sociology quadrants, since we can specify who the audience is with more detail than Burawoy allows us. We can look at public and institutional consumers of knowledge that have different core interests and operating principles (schools, states, businesses, etc.), and see how that impacts both the production and dissemination of knowledge for different disciplines, based on their different institutional ties. We can begin to understand knowledge production across disciplines that have linkages to a range of institutions, and for a variety of purposes. We can move towards the questions about knowledge for what, knowledge about what, and knowledge for whom.

In addition, there is the issue of national differences. When you consider a comparison across nations, you can begin to talk about how Brazilian sociology, for example, is heavily (almost exclusively) public (Baiocchi, 2004), compared to American sociology, which has an enormous professional presence that tends to dwarf other types of sociology. Why should policy or professional sociology in different countries be represented as having the same size in a $2 \times 2$ table, however, when it is obvious that the size of a nation's professional sociology is a variable that differs across national boundaries and histories, something that even Burawoy has tirelessly pointed out? More policy work is done in sociology in some nations than in others. And the distinct university systems in which academic disciplines are embedded differ in comparative terms - universities in France are national state-run institutions, while they are provincial enterprises in Canada and a mixture of private organizations and state institutions in the USA. Our alternative to Burawoy is attempting to capture these complexities in a visual and, ultimately, empirical way. 


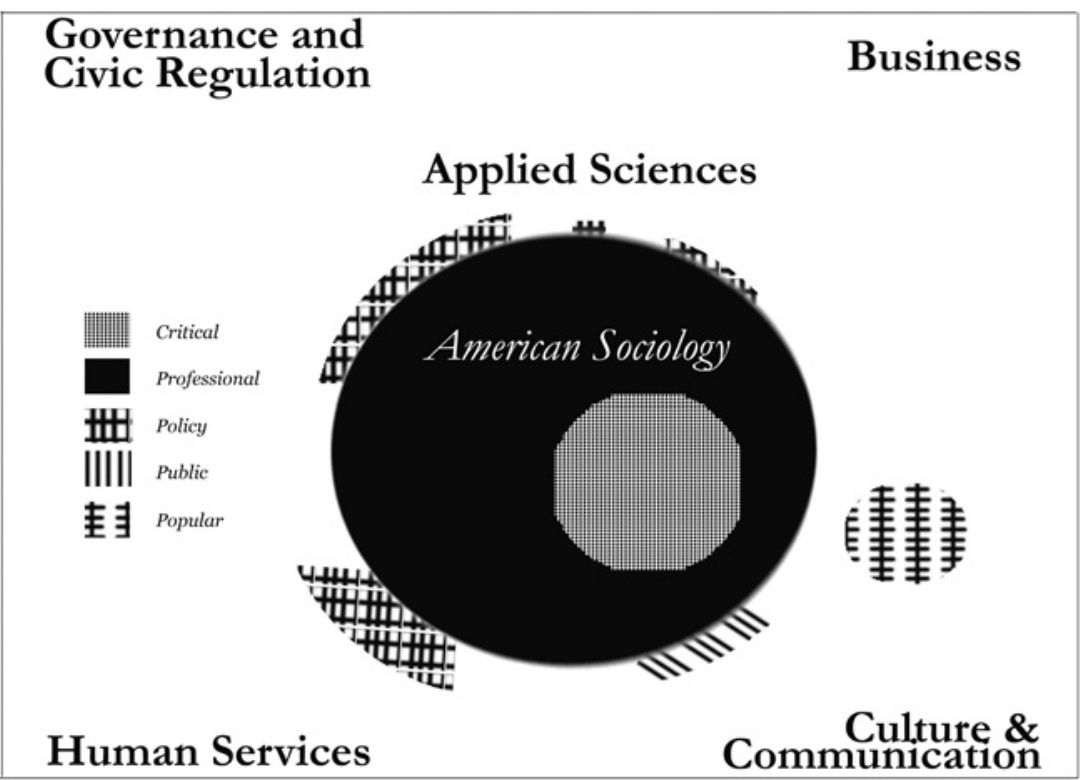

Figure 2 American sociology in its institutional context

In the next figures, we demonstrate the contextualizing and comparative potential of our model by illustrating the differences in disciplinary character between sociology in the USA (Figure 2) and Canada (Figure 3), and between sociology and economics (Figure 4) in the USA. These models are still conceptual, but the empirical possibilities are clear, as we suggest with regards to British sociology. Once we are able to operationalize the categories in Burawoy's model and link these measures to audience and extra-academic institutional characteristics (by measuring tasks performed by academics, or the influence of their writings), we will be well on our way to an empirical picture of the ways that disciplines and academics compare to each other, and relate to various audiences and institutions with whom they interact.

In all cases, the university or discipline has been located relatively centrally, and its various 'tasks' have been mapped in such a way as to indicate their ties to different spheres of social purpose. Figure 2 is a representation of contemporary American sociology with its proportionally large professional core on which all three of Burawoy's other tasks are dependent. This is a historical process: sociology started in the USA in the human service sphere as a spin-off from Protestant theology and reform-oriented social work. Today, sociology departments in the USA are highly professionalized, especially at the more elite research universities. Critical sociology is contained entirely within the professional core, because its audience is exclusively academic - critical sociologists debate with other sociologists regarding the moral implications of their own professional practice. Within sociology, the critical element of the discipline is 
large and close to the center of the profession - critical sociologists like to emphasize their marginality, but the perspectives of C. Wright Mills, Alvin Gouldner, and Dorothy Smith are relatively well known in the discipline, widely discussed in textbooks, and are cited in core journals. The frequency of debates within our discipline regarding the 'crisis of sociology' in books and articles over the years is a measure of the centrality of the critical wing of the discipline. In comparative terms, sociologists argue more about the moral implications of our professional practice than most academic disciplines (economics, philosophy, etc.). Policy sociology is linked to the professional core (since the skills employed in policy sociology come from our professional training), and there are many ties to government and states (governance sphere), a small number to the private sector (business sphere concerns), and very large links to social welfare and education (human services sphere) concerns.

Public sociology is linked primarily to the culture and communications sphere's commercial book presses, newspapers, popular magazines, elite journals, radio, and television. Public sociology that retains ties to professional sociology gets respect from inside the sociology profession, at least from scholars committed to this kind of work. The public sociology of both Vaughan and Epstein represents examples from the American case, discussed above. 'Pop'(ular) sociology involves sociological questions being addressed by journalists or other intellectuals who have entered into a debate on a sociological issue; or sociologists who are speaking outside of their area of actual expertise, commenting on matters of sociological interest, but not speaking as an expert on that specific topic and thus not recognized in the professional core. The most famous example (Horowitz, 1994) of boundary conflicts and policing between 'real' sociology and 'pop sociology' in American sociology is the case of Vance Packard - a journalist who sold millions of copies of numerous books in mid-century America on sociological themes of class inequality, status anxiety, and consumerism. The fact that sociologists do not control the distribution of books in the culture and communication sphere (note the disappearance of sociology sections in many book stores today, replaced by cultural studies or social and cultural theory sections) helps account for the sometimes vehement opposition from professional sociologists to any whiff of the popularization of their craft. Despite the tension that exists between public and professional sociology in our discipline, American sociologists have produced a relatively large amount of work that does get consumed in the market-place for ideas in the culture and communications sphere - think of David Riesman's The Lonely Crowd (1950), Robert Bellah's (1985) Habits of the Heart and various of Richard Sennett's (e.g. 1998) works. These works are public sociology in our terms, because they retain links to professional sociology unlike the case of Packard's pop sociology.

Canadian sociology is quite similar to American sociology, in international comparative terms, but we hypothesize that the professional base of Canadian sociology is smaller and less developed than that of American sociology. Canadian sociology only really emerged as an institutionalized discipline in most 


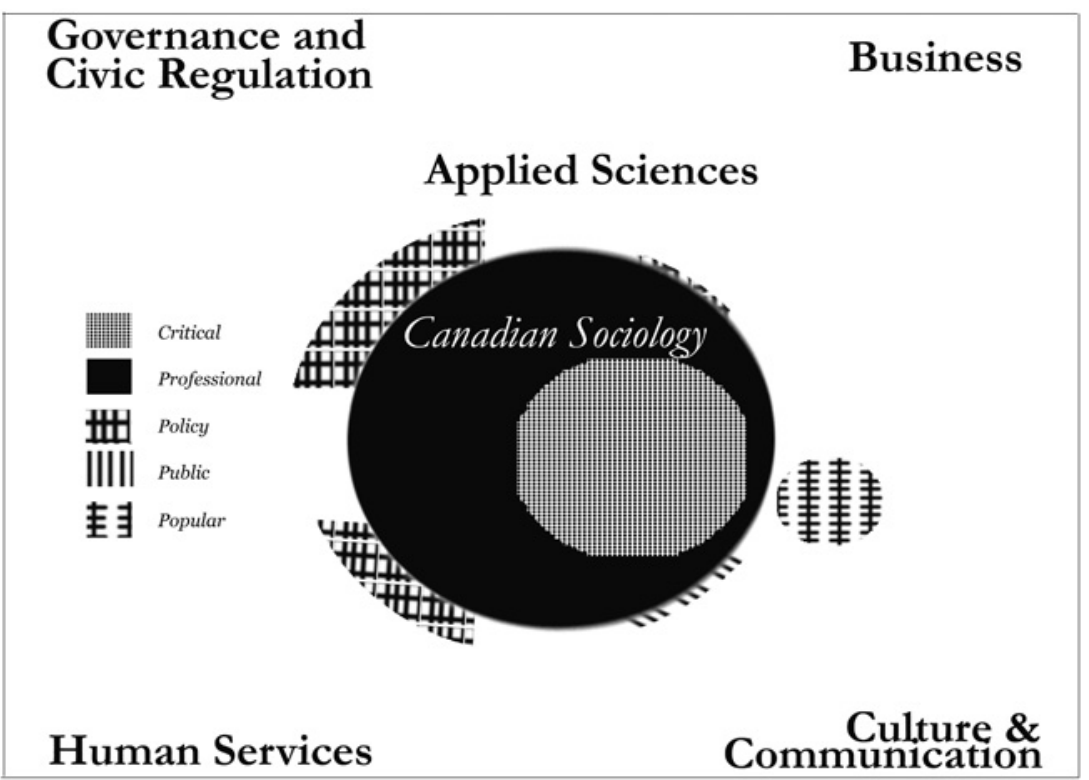

Figure 3 Canadian sociology in its institutional context

of Canada in the 1960s, so there is a less developed research core. Because Canadian universities are all essentially public and are embedded in a relatively 'flat' institutional environment (Davies and Hammack, 2005) that does not have elite private schools driven by massive endowments (like Harvard or Yale) or equivalent access to wealthy foundations as in the USA, there are fewer resources available to isolate the professional research core of the discipline from the needs and demands of policy makers and students. On the other hand, Canadian sociology has a relatively large critical component relative to American sociology (McLaughlin, 2004). The Canadian tradition of political economy is proportionately much larger in Canada than the Marxist sociology equivalent in American sociology (Clement, 2001). One could argue that critical feminist sociology is stronger in Canada than in the United States (Brym and Fox, 1989; Eichler, 2002; but see McLaughlin, 2004).

Policy sociology is also larger in Canada than in the USA in proportional terms, we suspect, since a wing of the Canadian federal government (the Social Science and Humanities Research Council) is the major source of research funding here, shaping hiring and tenure/promotion decisions in ways that would not occur in top departments in the United States. Because of the reliance of Canadian sociologists on state funding, our scholars do a lot of consulting work with government agencies or government reports on various types of social policy, especially on health care questions as opposed to criminology, which often dominates American policy sociology for obvious structural and historical reasons. We are not without public sociologists in Canada, but public sociology is 
not even as significant in Canada as in the United States, and certainly nothing close to Baiocchi's (2004) perception of the dominant public nature of Brazilian sociology. We hypothesize that public-oriented academics in Canada (as in England and Australia) tend to come out of philosophy and history respectively, as well as from political science. Our public sociology tends not to get the same level of elite media attention and high-end commercial press publication rates as what Burawoy calls 'traditional public sociology'. There is, however, a range of what Burawoy calls 'organic public sociology' in Canada, as intellectuals linked to social movements and social democratic parties write works designed to shape public opinion in Canada on questions of health care, welfare state policy, gender and race/immigration issues (Nock, 2001). American sociology could perhaps be characterized as primarily professional with critical, public and policy considerations being secondary. Canadian sociology is still primarily professional, but not so overwhelmingly so, and has a very strong policy component, a relatively strong critical wing, but only a small traditional public sociology element to our practice. These hypothesized patterns remain to be tested empirically, but the model we have proposed allows for the framing of the issues that could be tested with empirical measures regarding writing in newspapers, media coverage of scholar's work and policy reports written. The centrality of 'critical' sociology could be measured by the citation patterns of widely recognized 'critical sociology' texts in core disciplinary journals, something that would likely differ by national sociology.

We suspect that British sociology would look more like Canadian sociology than the American model (Abrams, 1968; Halsey, 2004; Platt, 2003). The Fabian-like policy research so important in Canada is, of course, derived originally from early 20th-century British poverty reform and research, a traditional of policy sociology that retains vitality today. In addition, Marxist and cultural studies-oriented critical sociology represent an important element of the British version of the discipline, suggesting an even larger critical core across the Atlantic than in Canada and certainly than in the United States. It is our impression that British sociologists are less likely to do policy work with the private sector than the sub-field of organizational studies does in the USA (a very small element of the discipline, in Canada). Canadian sociology has no scholar who has attained the level of national visibility that Giddens has in Britain, whatever one thinks of the value of his scholarship and political interventions; the public element of the British discipline may well be larger than the Canadian. While the cultural self-understanding of British intellectuals tends towards what Collini (2006) has called a 'Dreyfus envy' that suggests that public intellectuals are absent in Britain unlike in France, from a Canadian perspective this seems overblown (see also Turner, 2005). Clearly, more research is required to substantiate these speculations with empirical data, but we have suggested a model that could facilitate comparative empirical research.

Burawoy's model for public sociology not only helps us understand sociology and its publics, it also provides analytic leverage for understanding public academic life in the modern university more generally. As part of a larger project 


\section{Governance and \\ Civic Regulation}

\section{Business}

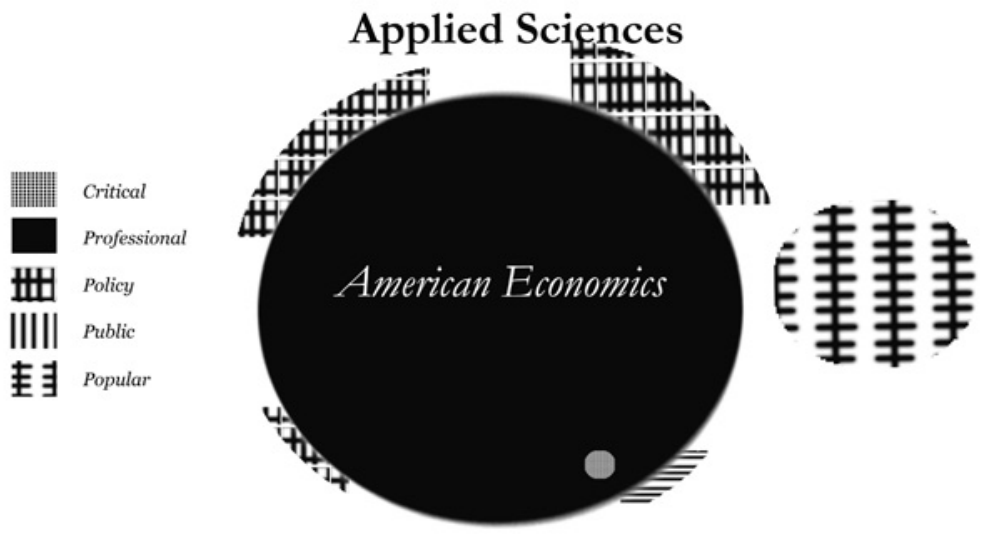

Human Services

Culture \&
Communication

Figure 4 American economics in its institutional context

where we are empirically examining the role that Canadian academics play as public intellectuals and developing a model for understanding disciplinary differences, we offer some preliminary thoughts on how economics compares to sociology on these questions.

\section{Economics as a Technical-Professional Science}

American academic economics and American sociology share a striking dominance of their professional type. That is where the similarity ends. Compared to sociology, the critical and the public wings of the economics discipline are nearly non-existent. The critical vein in economics is marginalized - non-central, small, and relatively inactive. American economics has an enormous policy presence, however, for both government and private sector applications (economists, nevertheless, are far more likely to work on private sector policy than sociologists). Economists also work on health care, education, and social work policy, but far less often than do sociologists

The reason for the marked dominance of the professional sphere (and, in some ways, the strength of the policy sphere as well) is that the language of economics is technical and scientific. The boundary between professional and public is relatively impermeable. It is thus more difficult to transport economic terms into the public realm. With few exceptions (John Kenneth Galbraith, Milton Friedman, and Paul Krugman), economists rarely intentionally engage the public directly. 
Those that do are often isolated from the pressures of professionalization by elite status and Nobel Prizes. There is not as much of a market for public economics written by economists as there seems to be for public sociology, public psychology or public history; this is a hypothesis that could be tested empirically by measuring book sales. There are massive numbers of popular self-help books on personal finances, management strategies, and investing (thus accounting for the size of popular economics represented here), but they tend to be written by noneconomists since the economics profession itself shows little interest in and does not reward this kind of activity.

\section{Looking at Our Public Face(s):The Sociology of Public Academics}

What we have attempted to offer in these few pages, is a rationale for looking beyond a debate about whose politics are superior, and whether or not society needs to be told what to do by sociologists. Giving examples of the work people do as public sociology (a common element in the published responses to Burawoy), while interesting, does not further the debate in analytic terms. Arguing 'for' and 'against' Burawoy and his vision for public sociology is not deepening our understanding of what public sociology is, and what it can do, in ways that are empirically interesting and useful. While it is certainly important to argue the normative issues, it will be ultimately more productive to think analytically and comparatively about our discipline. The model we have presented allows a starting point to do just that and more importantly, it offers the opportunity to truly provincialize not just sociology, but all academic disciplines and forms of scholarly (interdisciplinary forms of knowledge, for example, and applied academic units) and non-academic forms of intellectual production (think tanks, for example) by developing a general theory of knowledge production that does not simply universalize the particularities of the American context.

The conceptual models we have offered of American and Canadian sociology and American economics are approximations at this point. The next step, as we have indicated, is to operationalize the contested terms that are thrown about in the discussion about public sociologies: policy, critical, reflexive, and public. Once this is accomplished, our next project is to begin to profile disciplines by starting with individual academics, and building aggregated pools of data about the types of work they do, and the ways in which that work is accomplished and embedded in the larger intellectual, political, and social landscape. Our alternative model will allow us to compare disciplines and forms of knowledge in different countries in ways not possible using Burawoy's $2 \times 2$ table. It is a large, ambitious project, but one which we believe will yield useful analytic leverage on knowledge production and public academic and public intellectual activity beyond the case of sociology and its publics. 


\section{Acknowledgements}

This article comes out of research generously funded by the Canadian Social Science and Humanities Research Council (SSHRC) as part of a larger project on 'Canadian Professors as Public Intellectuals'. Neil McLaughlin presented earlier and related versions of the arguments outlined here at the University of Western Ontario, the University of Toronto, the University of Western Australia, University College Dublin, Vytautas Magnus University in Lithuania and in a special presidential session at the American Sociological Association annual meetings in Montreal in 2006. The funding of the SSHRC MCRI project on 'Globalization and Autonomy' directed by William Coleman at McMaster University helped enormously, as we endeavor to think about public academics in a wider comparative and global framework. Neil McLaughlin particularly wants to acknowledge the hospitality and critical dialogue he experienced at recent speaking engagements at Loughborough, Leicester and the Open University in Great Britain. Sina Rahmani's research assistance was invaluable.

\section{Notes}

1 There are some exceptions, of course. Calhoun (2005: 358) suggests that Burawoy's model does not capture the complexity of the link between sociology as a discipline and the world that it studies. Another significant challenge to the $2 \times 2$ table comes from Kalleberg (2005), who criticizes the model Burawoy employs because it cannot be used to model disciplines in a general way.

2 See McLaughlin et al. (2005) for a detailed discussion of this issue. In short, it is difficult to see how public sociology could possibly be inherently reflexive when one considers the various market, fame/status, and political pressures that come to bear when engaging a public audience.

3 Other than Ghamari-Tabrizi (2005: 362), who observes that Burawoy's $2 \times 2$ table is 'crude' and may not capture interdisciplinary subtleties, and Baiocchi's (2004) comment that Brazilian sociology is predominantly public and does not resemble American sociology, criticisms in this vein are rare.

4 We have called this sphere 'Governance and Civic Regulation' in our models that follow.

5 One could measure the location of each discipline in a variety of ways: the 'sphere of social purpose' location of the jobs taken by undergraduate or graduate students or the number of grants or consultations done by faculty related to different spheres would be two obvious first steps.

\section{References}

Abrams, P. (1968) The Origins of British Sociology: 1834-1914. Chicago, IL: University of Chicago Press.

Acker, J. (2005) 'Comments on Burawoy on Public Sociology', Critical Sociology 31(3): 321-31.

Baiocchi, G. (2004) 'Interrogating Connections: From Public Criticisms to Critical Publics in Burawoy's Public Sociology', Critical Sociology 31(3): 339-51. 
Bellah, R., R. Madsen, W. Sullivan, A. Swidler and S. Tipton (1985) Habits of the Heart: Middle America Observed. London: Hutchinson.

Brint, S. (1994) In an Age of Experts. Princeton, NJ: Princeton University Press.

Brym, R. and B. Fox (1989) From Culture to Power: The Sociology of English Canada. Toronto: Oxford University Press.

Burawoy, M. (2005) 'For Public Sociology', American Sociological Review 70(1): 4-28.

Calhoun, C. (2005) 'The Promise of Public Sociology', British Journal of Sociology 56(3): 355-63.

Clement W. (2001) 'Canadian Political Economy's Legacy for Sociology', Canadian Journal of Sociology 26(3): 405-20.

Collini, S. (2006) Absent Minds: Intellectuals in Britain. Oxford: Oxford University Press.

Davies, S. and F. Hammack (2005) 'The Channelling of Student Competition in Higher Education: Comparing Canada and the United States', Journal of Higher Education 76(1): 89-106.

Eichler, M. (2002) 'Feminism and Canadian Sociology', The American Sociologist 33(1): 27-41.

Epstein, C.F. (1981) Women in Law. New York: Basic Books.

Ghamari-Tabrizi, B. (2005) 'Can Burawoy Make Everybody Happy? Comments on Public Sociology', Critical Sociology 31(3): 361-9.

Halsey, A.H. (2004) A History of Sociology in Britain: Science, Literature, and Society. New York: Oxford University Press.

Horowitz, D. (1994) Vance Packard and American Social Criticism. Chapel Hill: University of North Carolina Press.

Kalleberg, R. (2005) 'What is "Public Sociology"? Why and How Should it be Made Stronger?' British Journal of Sociology 56(3): 387-93.

Lynch, M. (2000) 'Against Reflexivity as an Academic Virtue and Source of Privileged Knowledge', Theory, Culture and Society 17(3): 26-54.

McLaughlin, N. (2004) 'A Canadian Rejoinder: Sociology North and South of the Border', The American Sociologist 35(1): 80-101.

McLaughlin, N., L. Kowalchuk and K. Turcotte (2005) 'Why Sociology Does Not Need to be Saved: Analytic Reflections on Public Sociologies', The American Sociologist 36(3-4): 133-51.

Nock, D. (2001) 'Careers in Print: Canadian Sociological Books and Their Wider Impact, 1975-1992', Canadian Journal of Sociology 26(3): 469-85.

Platt, J. (2003) The British Sociological Association: A Sociological History. Durham, UK: Sociologypress.

Riesman, D. (1950) The Lonely Crowd: A Study of the Changing American Character. New Haven, CT: Yale University Press.

Sennett, R. (1998) The Corrosion of Character: The Personal Consequences of Work in the New Capitalism. New York: Norton.

Tittle, C. (2004) 'The Arrogance of Public Sociology', Social Forces 82(4): 1639-43.

Turner, J. (2005) 'British Sociology and Public Intellectuals', British Journal of Sociology 57(3): 169-88.

Vaughan, D. (1986) Uncoupling: Turning Points in Intimate Relationships. New York: Oxford University Press.

Vaughan, D. (1996) The Challenger Launch Decision: Risky Technology, Culture, and Deviance at NASA. Chicago, IL: University of Chicago Press. 
Vaughan, D. (2006) 'NASA Revisited: Theory, Analogy, and Public Sociology', American Journal of Sociology 112(2): 353-93.

\section{Neil McLaughlin}

Teaches sociological theory at McMaster University (Hamilton, $O N$ ), and publishes in the sociology of culture, intellectuals, and knowledge. In addition to studying both Canadian intellectual life and sociology, he is working on questions relating to 'global public intellectuals' and the issue of marginality and the social origins of creativity. His most recent publication is 'Orwell, the Intellectuals and the Academy' in the Cambridge Companion to Orwell (edited by John Rodden, Cambridge University Press, 2007). He has a piece forthcoming in the Canadian philosophy journal Dialogues which discusses Erich Fromm's classic 194 I book Escape from Freedom (Fear of Freedom, in Britain) in light of contemporary Popperian critique.

Address: Neil McLaughlin, Associate Professor, Sociology, McMaster University, KTH 620, 1280 Main Street West, Hamilton Ontario, L8S 4M4 Canada.

E-mail: nmclaugh@mcmaster.ca

\section{Kerry Turcotte}

Is a doctoral candidate in sociology at McMaster University. Her current work involves looking at the differences between Canadian sociology and anthropology professors as public intellectuals. Her broader research agenda includes what she calls 'sustainable' forms of interpersonal violence, the sociology of knowledge and creativity, and sociological theory. 